\title{
LOS PAGI, ESTRUCTURAS TERRITORIALES BÁSICAS EN LA ORGANIZACIÓN ADMINISTRATIVA ROMANA ${ }^{1}$
}

\author{
María Lourdes Martínez de Morentin ${ }^{2}$
}

1 Este trabajo se enmarca, en una línea de investigación continuadora de las publicaciones programáticas sobre derecho administrativo y fiscal romano desarrolladas por el Profesor Dr. Antonio Fernández de Buján, catedrático de Derecho Romano de la Universidad Autónoma de Madrid y académico de número de la Real Academia de Jurisprudencia y Legislación. Fruto de su magisterio ha surgido una fecunda línea de investigación en la que destaca su labor de dirección y coordinación de varios proyectos de investigación estatales sobre esta materia y la publicación de cuatro libros colectivos que recogen las contribuciones en estos campos de la romanística española e internacional: Derecho administrativo bistórico, Santiago de Compostela, 2005; Hacia un derecho administrativo y fiscal romano, Madrid, 2011; Hacia un derecho administrativo y fiscal romano II, Madrid, 2013, y Hacia un derecho administrativo y fiscal romano III, Madrid, 2016, que recogen las actas de las Jornadas de Derecho Administrativo, Medioambiental y Fiscal Romano realizadas en Vigo, Madrid, Valencia y Turín. Algunas de las contribuciones en las que el profesor Fernández de Buján expone las líneas maestras de la investigación romanística en este campo son: "Perspectivas de estudio en temática de derecho administrativo romano surgidas a tenor del pensamiento y de la obra de Giambattista Impallomeni", Index 26, Nápoles, 1998, pp. 463 ss.; "Ius fiscale: instrumentos de política financiera y principios informadores del sistema tributario romano", IVRA, Nápoles, 58, 2010, pp. 1-32; "Hacia un tratado de derecho administrativo romano", SDHI, Roma, 77, 2011, pp. 441-478; Derecho público romano, 18. ${ }^{a}$ ed., Cizur Menor (Navarra), 2015. Gracias a su impulso nació en España la prestigiosa colección de monografías de "Derecho Romano y Cultura Clásica" (Edit. Dykinson), que dirige, y que comprende casi un centenar de monografías de autores españoles y extranjeros; más de una veintena tienen por objeto, específicamente, materias de derecho administrativo medioambiental y fiscal romano; además, bajo su dirección se han publicado en la Revista General de Derecho Romano (www.iustel.com), a lo largo de casi quince años, numerosos estudios sobre esta temática.

2 Doctora en Derecho, profesora de Derecho Romano, Departamento de Derecho Privado de la Facultad de Derecho de la Universidad de Zaragoza, Zaragoza, España. Correo-e: lmarmor@unizar.es Fecha de recepción: 7 de julio de 2016. Fecha de modificación: 2 de septiembre de 2016. Fecha de aceptación: 15 de septiembre de 2016. Para citar el artículo: Martínez de Morentin-Llamas, M. L. "Los pagi, estructuras territoriales básicas en la organización administrativa romana", Revista digital de Derecho Administrativo, n. ${ }^{\circ} 16$, segundo semestre, Universidad Externado de Colombia, 2016, pp. 117-144. DOI: http://dx.doi. org/10.18601/21452946.n16.08. 


\title{
RESUMEN
}

Este artículo trata sobre los pagi, estructuras rurales elementales, que se encuentran ya en los primeros tiempos de Roma. Además de resaltar la doctrina actual sobre el tema, se examinan varios textos que sirven de apoyo para las conclusiones finales que tratan de aportar luces sobre la finalidad del pagus. Los textos, ordenados cronológicamente, son: la tabula Veleiana, la lex rivi Hiberiensis, una sentencia judicial del año 193 d.C., un pasaje de Ulpiano y varios fragmentos de Siculo Flacco.

Palabras clave: Pagi, tabula alimentaria, Gromáticos, centuriatio, Administración.

\section{The pagi, Basic Territorial Structures in the Roman Administrative Organization}

\begin{abstract}
This article is about the pagi, basic rural structures, established in the early days of Rome. In addition to highlighting the current doctrine on the subject, this paper will examine several texts that support its final conclusions in order to shed light on understanding what a pagus is. The texts, in chronological order, are: the tabula Veleiana, the lex rivi Hiberiensis, a judgment from the year 193 A.D., a passage by Ulpiano and several shorter passages by Siculo Flacco.

Keywords: Pagi, tabula alimentaria, Gromatics, centuriatio, Administrative Organization.
\end{abstract}

\section{INTRODUCCIÓN}

Las investigaciones sobre las estructuras e instituciones rurales de la administración territorial romana han conocido un interés renovado en los últimos años. Gracias a nuevos trabajos de investigación ${ }^{3}$ caracterizados por una rigurosa aproximación historiográfica, se ha llegado a la deconstrucción de la

3 LUIGI CAPOGROSSI COLOGNESI. Persistenza e innovazione nella strutture territoriali dell'Italia romana. Napoli, 2002; LuIGI CAPOGROSSI COlOGNESI, "Pagi, vici e fundi nell'Italia romana", Athenaeum 90, 2002, pp. 45-58; JUAN Miguel AlBURQUERQUE, "Concentración y ordenación urbanística del territorio romano: colonias, conventos y municipios de la Bética", Hacia un Derecho Administativo y Fiscal Romano, Madrid: Dykinson, 2011, pp. 77-113. De manera general, sobre la experiencia administrativa romana, vid. ANTONIO FERNÁNDEZ DE BUJÁN, Derecho público romano, 18. ${ }^{a}$ ed., Cizur Menor (Navarra): Civitas Thomson Reuters, 2015, pp. 271-310. 
categoría pagus-vicus ${ }^{4}$, generalmente utilizada por los estudiosos como la clave interpretativa de las estructuras territoriales prerromanas, y a un correcto encuadramiento de las mismas. Han contribuido a ello nuevos análisis de los testimonios literarios, el auge de los comentarios al corpus gromático ${ }^{5}$ y recientes hallazgos epigráficos ${ }^{6}$, que suministran datos muy interesantes sobre una figura incierta, el pagus, y sobre su organización.

Para comprender mejor el tema sería preciso abandonar la antigua visión ${ }^{7}$ que se tenía del pagus, como mera recepción y parcial reutilización de estructuras autóctonas en la nueva organización territorial romana ${ }^{8}$, y tener en cuenta los estudios actuales que, desde otra perspectiva, han contribuido a su esclarecimiento 9 . Sin embargo, las cuestiones relativas a su naturaleza jurídica o a su importancia desde el punto de vista de la Administración romana, tanto en los territorios itálicos como en las provincias, siguen siendo un enigma que los investigadores intentan desentrañar.

4 Para un estudio en profundidad vid. MARÍA LuISA CORTIJO CEREZO. El pagus en la administración territorial romana. Los pagi de la Bética. Florentina Iliberritana, 2, 1991, pp. 105 ss.; Michel TARPIN, Vici et pagi dans l'occident romain, Roma, coll. EFR, 2002; SIMONE SISANI, In pagis forisque et conciliabulis. Le strutture amministrative dei distretti rurali in Italia tra la media repubblica e l'età municipale, Atti della Accademia Nazionale dei Lincei, serie IX, vol. XXVII, fascicolo 2, Roma, 2011, pp. 551-780.

5 Remo MarTinI, "Il pagus romano nella testimonianza di Siculo Flacco", en Rendiconti dell'Istituto Lombardo, Milano, 107, 2, 1973, pp. 1041-1056; Luigi CAPOGROSSI COLOGNESI, "Le forme gromatiche del territorio e vari regimi giuridici dell'ager Romanus e dell'ager colonicus. Il complesso mosaico della romanizzazione italica" en VV.AA., Gli Statuti Municipali, Pavía: IUSS Press, a cargo de LUiGi CAPOGROSSI COLOGNESI y GABBA E., 2006, pp. 579-604.

6 Nos referimos sobre todo a la lex rivi Hiberiensis; vid. ARMANDO TORRENT, "Estructuras políticas menores en la tarraconenese de época adrianea: el pagus en la lex rivi Hiberiensis" Revista Internacional de Derecho Romano (RIDROM), www.ridrom.uclm.es, 2014 (=IURA LXII, 2014); también PATRICK LE ROUX, "Le pagus dans la péninsule Ibérique", en Chiron XXXIX, 2009.

7 Adolf Schulten, “Die Landgemeinden im römischen Reich”, en Pbilologus, 53, 1894, pp. 629-634. En este sentido, Federico SanTANGElO, "Confini di città e confini di pagi nell'Italia romana. Il problema del "dualismo Limitaneo" en Gli Statuti Municipali, a cargo de Luigi Capogrossi Colognesi y GabBa, E., pp. 615-626.

8 Luigi CAPOGROSSI COlOGNeSI, "I sistemi delle servitù d'acqua in diritto romano", en Lex rivi Hiberiensis. Diritto e tecnica in una comunità di irrigazione della Spagna romana, Milano: Jovene, Università catolica del Sacro Cuore, LAURETTA MAGANZANI y CH. BuZZACHI (eds.), 2014, p. 78.

9 María Luisa Cortijo Cerezo, "El pagus en la administración territorial romana. Los pagi de la Bética", cit., pp. 105 ss.; María José CASTILLO PASCUAL, Espacio en orden: el modelo gromático de ordenación del territorio, Logroño, Universidad de la Rioja, 2011, pp. 242-261. 
TARPIN $^{10}$, recientemente, en su artículo $A$ cosa serve un pagus? Bilancio e nuove questioni ${ }^{11}$, al hacer una revisión sobre el tema, considera superada la vieja teoría del pagus tribal, céltico o itálico y prerromano, como una realidad sa$\mathrm{cra}^{12}$, y señala que, a pesar de que cada cierto tiempo aparece un arqueólogo intentando revivirla, forzando el texto de César ${ }^{13}$ e ignorando los trabajos históricos y epigráficos de los últimos años, la idea del pagus ha evolucionado hasta llegar, en nuestros días, a ser entendida como una realidad absolutamente romana, un ente territorial con fines censuales, administrativos y fiscales ${ }^{14}$. En este sentido dice Tarpin: "pagus es una estructura territorial dotada de límites generalmente naturales, pero sobre todo perenne y validada cada año por los magistrados, desarrollada a instancias de la conquista del Imperio por necesidades del censo y la fiscalidad".

Cortijo Cerezo señalaba en 1991 que "pagi aparece más documentado cuando se refiere a divisiones territoriales con funciones concretas en el ámbito catastral, entes plenamente integrados en el organigrama romano y sin connotaciones ni sentido étnico"15. Según De Pachtère, "el pagus es un territorio natural con una pertenencia clara, apoyada sobre diversos elementos del relieve y la hidrografía, pero puede también corresponder al territorio de una

10 Entre sus obras, que contribuyen al estudio de los pagi, MiCHEL TARPIN, Vici et pagi dans l'occident romain, Roma, coll. EFR, 2002; MICHEL TARPIN, "Strutture territoriali romane: tra complessità ed efficienza", Gallorum Insubrum fines: ricerche e progetti archeologici nel territorio di Varese, Roma, en B. Grassi, M. PIZZO (ed.), 2014, pp. 199-207; Michel TARPIN, "La lex rivi Hiberiensis: une restitution graphique de l'incipit", en Zeitschrift fur Papyrologie und Epigrapbik 192, 2014, pp. 265-272.

11 Michel TARPIN, "A cosa serve un pagus? Bilancio e nuove questioni" en Tra l'Adriatico e le Alpi: forme e sviluppi dell'organizzazione territoriale e dei processi di integrazione nella $X$ regio orientale e nelle regioni contermini, S. MAGNANI (ed.), (convegno, Udine, 3-5 ottobre 2012) (en prensa). Agradezco al autor que me haya permitido la consulta antes de su publicación. Las páginas citadas pertenecen, por tanto, a dicho texto.

12 Una historiografía del concepto pagus puede verse en Luigi CAPOGROSSI COLOGNESI, "Pagi sanniti e centuriatio romana", en Ager Campanus. Atti del Convegno internazionale, Real Sito di San Leucio, 8-9 de junio 2001, a cargo G. Franciosi, Napoli: Jovene editore, 2002, pp. 77-93. Aspectos relevantes y bibliografía sobre el pagus en LUIGI CAPOGROSSI COLOGNESI, "I sistemi delle servitù d'acqua in diritto romano" en, Lex rivi Hiberiensis. Diritto e tecnica in una comunità di irrigazione della Spagna romana" cit. pp. 75-91. Un profundo estudio sobre vici y pagi en MiCHEL TARPIN, "Vici et pagi dans l'occident romain", cit, ${ }_{, i}$ en el elenco de los pagi faltan los referidos en la lex rivi Hiberiensis ya que el autor no tuvo noticia del hallazgo del bronce hasta más tarde.

13 Caes. Bellum Galli, 6,11,2: In Gallia non solum in omnibus civitatibus atdue in omnibus pagis partisbusque, sed paene etiam in singulis domibus factiones sunt. 6,23,5: In pace nullus est communis magistratus, sed principes regionum atque pagorum inter suos ius dicunt controversiasque minuunt. Vid. MICHEL TARPIN, Vici et pagi dans l'occident romain, cit., pp. 33-37.

14 GÉRARD CHOUQER, "Arpentage, cadastre et fiscalité foncière, de l'Antiquité à l'époque moderne", Etudes rurales, 2008/1, n. ${ }^{\circ} 181,203-236$.

15 María Luisa CoRTIJO CEREZO, "El pagus en la administración territorial romana. Los pagi de la Bética", cit., p. 105, si bien, como lo evidencia el título mismo, en relación a la Bética. 
comunidad integrada en una nueva ciudad"16. Por su parte, Sisani, en un interesante trabajo de 2011, ha dado una definición de pagus con la que concuerdan casi todos los autores: "Il pagus è una unità teritoriale, strutturata sul piano ideologico e istituzionale come un contenitore: una pura dimensione spaziale dunque, che si concretizza nella specifica funzione di inquadrare - territorialmente ed istituzionalmente - le diverse realtà materiali in essa contenute, sulle quali si articola la vita economica e sociale dei pagani"17.

La autora ${ }^{18}$ aporta algunos datos diferenciales con otras estructuras elementales del ager Romanus extra urbano que aparecen en las fuentes literarias. Así, al examinar los fora et conciliabula, mencionados en distintos pasajes de Tito Livio, señala que estos eran los lugares de reunión de los ciudadanos romanos establecidos sobre el ager Romanus, mientras que pagus sería la estructura territorial y administrativa.

La idea de que la palabra pagus hubiera definido diversos conceptos, según se tratase o no de las provincias del Imperio, ha ido siendo abandonada progresivamente ${ }^{19}$. Mentxaca señala que "podríamos definirlo también con la acepción que hace referencia a una circunscripción rural con cierta independencia en su administración, y por lo tanto, completamente diferente de la propia entidad que podría representar la ciudad"20. A su vez, Castillo Pascual considera que "son unidades menores de ordenación del territorio, muy útiles para la política financiera llevada a cabo por Roma"21.

Algunos autores ${ }^{22}$ sostienen que debería admitirse que el pagus de la Antigüedad fue verdaderamente el predecesor del pagus medieval, considerado

16 Félix-Georges De Pachtère, La table bypothécaire de Véléia, Paris, 1920.

17 SIMONE SISANI, In pagis forisque et conciliabulis. Le strutture amministrative dei distretti rurali in Italia tra la media repúbblica e l'età municipale, cit., pp. 551-780.

18 Ibíd., pp. 598-600.

19 Michel TARPIN, A cosa serve un pagus?, cit., 2.

20 Rosa MENTXACA, "Lex rivi Hiberiensis, derecho de asociación y gobernador provincial", RIDROM, 2009, nota 17, disponible en: www.ridrom.uclm.es Según los especialistas, el término pagus se encuentra sobre todo en epigrafía procedente de tres partes del Imperio (Italia, Galia y África), es de difícil interpretación y tendría diferentes de significados según su evolución. Para Hispania (LeOnARD A. CurChin, "Vici and pagi in Roman Spain", en REA 87, 1985, 342) los pagi eran distritos rurales creados por la admisitración romana en áreas romanizadas como la Bética o el valle del Ebro, en ocasiones atribuidos a una ciudad, mediante los que se haría referencia a la organización del espacio rural en el que había una población agraria organizada y sometida a obligaciones fiscales. Los pagi en cuanto distrito territorial cumplirían una serie de funciones religiosas, jurídicas, adminsitrativas, económicas, fiscales, censitarias, etc., y estaban organizados en parte como una ciudad, por lo que junto a los patronos, magistrados y flamines se mencionaba también el ordo.

21 María JosÉ CASTILlO PASCUAL, Espacio en orden: el modelo gromático de ordenación del territorio, cit., pp. 242-261, parece compartir la idea de CURCHIN sobre los pagi en Hispania al señalar en la p. 246: "Estaban situados en las zonas más ricas y pobladas en las que era necesario organizar un mayor número de población de cara a las imposiciones fiscales". 
claramente un elemento territorial y administrativo de la ciudad. Así, por ejemplo, aparece en las fuentes altomedievales como Gregorio de Tours: "el pagus es una unidad territorial, normalmente inferior a la ciudad"23. También puede ser usado el término como indicación topográfica, de este modo, una villa, por ejemplo, sería una especie de pagus ${ }^{24}$.

Los recientes trabajos sobre la ciudadanía y la colonización, basados en los textos gromáticos, han revelado la extraordinaria complejidad fiscal y jurídica del territorio de Roma, y al mismo tiempo, la sofisticación de su sistema censitario y fiscal, en el cual el pagus ocuparía un lugar relevante ${ }^{25}$. También la geografía, con su percepción de la realidad desde el punto de vista de la interacción entre comunidades y paisajes ${ }^{26}$, y la investigación arqueológica que contribuye, junto a la topografía, a la reconstrucción de las huellas de las antiguas centuriaciones, pueden aportar datos al complejo estudio del territorio controlado por Roma ${ }^{27}$. Además, nuevos hallazgos epigráficos, como la lex rivi Hiberiensis ${ }^{28}$, han impulsado de nuevo los estudios sobre estas estructuras y su encuadramiento dentro del esquema administrativo romano.

\section{LA TABULA ALIMENTARIA DE VELEIA}

La fuente antigua en la que se atestigua un gran número de pagi es la Tabula alimentaria de Veleia. Esta gran inscripción de época de Trajano (97-117 d.C.) recoge un amplio elenco de fundos declarados por los propietarios o possessores fundi de la zona como garantía hipotecaria frente a un préstamo de dinero dado por el emperador. La intención de la iniciativa financiera del emperador,

23 Gregorio De Tours, Historia francorum, 8, 18. Exinde dum pagum urbis in boc officio circuiret, in quadam villa a Werpino interficitur, disponible en: www.thelatinlibrary.com/gregorytours.html Michel TARPIN, "A cosa serve un pagus?", cit., 2

25 Michel TARPIN, "A cosa serve un pagus?", cit., 3. Parece que tuvieron gran importancia como base para el reclutamiento militar. La estrecha relación ente pagi y reclutamiento militar no va a ser abordada en este trabajo. Para su estudio vid. MiCHEL TARPIN, "Vici et pagi dans l'occident romain", cit. y Simone SISANI, In pagis forisque et conciliabulis, cit.

Vid. Michel TARPIN, "Vici et pagi dans l'occident romain", cit., 184-211.

27 LUIGI CAPOGROSSI COLOGNESI, "Le forme gromatiche del territorio e vari regimi giuridici dell'ager Romanus e dell'ager colonicus. Il complesso mosaico della romanizzazione italica" en Gli Statuti Municipali, cit. 583, nota 17.

28 Vid. la editio princeps, FRANCISCO BELTRÁN LLORIS, "An irrigation decree from Roman Spain: the Lex rivi Hiberiensis", The Journal of Roman Studies (JRS), 96, pp. 147-197, texto accesible en la Roman Law Library, http://droitromain.upmf-grenoble.fr/Negotia/rivi1_Lloris.htm última consulta 11/07/2016. Vid., últimamente MARía LOURDES MARTínEZ DE MORENTIN, "Aproximación al régimen jurídico de una comunidad de regantes: el bronce de Agón" en Fernández de Buján, A., (dir.) Andrea Trisciuglio y G. GereZ-KRaEmer, (coeds.) Hacia un Dereho Administrativo, Fiscal y Medioambiental Romano III, Madrid: Dykinson, 2016, pp. 323-349, con bibliografía actualizada. 
al parecer, era doble: de un lado, el sostenimiento de los niños indigentes de la comunidad mediante la devolución de los intereses periódicamente reclamados. El otro, conocido a través de la historia agraria de Italia durante el Imperio, era la incentivación de la productividad de los terrenos, que estarían vinculados al pago de los intereses mismos ${ }^{29}$.

Las tablas alimentarias, en las que se inscriben dichas operaciones financieras ideadas por el emperador, están redactadas siguiendo el procedimiento descrito por Ulpiano en su obra de censibus (D. 50.15.4 pr.) lo que demostraría el empleo, en una época anterior al momento en que escribe el autor, de estas estructuras elementales. Ulpiano simplemente plasmaría en su obra (de censibus) algo que ya se venía haciendo, es decir, señalaría la práctica de un orden establecido con anterioridad ${ }^{30}$. Así aparecen ${ }^{31}$ el nombre del fundo y al menos dos propiedades colindantes para evitar la confusión entre terrenos homónimos o pertenecientes al mismo propietario; el uso del suelo, los establecimientos

29 Elio Lo CASCIO, "Il princeps e il suo impero. Studi di storia amministrativa e finanziaria romana", Documenti e studi, Bari, 26, 2000, pp. 236-241, 274-276.

30 Luigi CAPOgrossi ColognesI, "Pagi vici e fundi nell'Italia romana", cit., 25-28; ID., "Pagi, vici e civitates nell'Italia romana", en Iuris vincula. Studi in onore di Mario Talamanca i, Napoli: Jovene editore, 2001, pp. 395-397, 418-431; Federico SANTANGELO, "Confini di città e confini di pagi nell'Italia romana", en Gli statuti municipali, cit., p. 616.

31 Vid. la Tabula de Veleia, CIL, XI, 1147, II, 8; NICOLA CRINITI, La tabula alimentaria de Veleia Parma, 1991, y en: www.veleia.it Contiene las disposiciones del emperador Trajano para instituir un préstamo hipotecario (concedido directamente del patrimonio personal del emperador, a los propietarios fundiarios de la zona), cuyos intereses iban destinados al mantenimiento de los niños y niñas más pobres. Esta operación financiera, ideada por Nerva (96-98 d.C.) y desarrollada por Trajano (98-117 d.C.), tenía como fin contribuir al sustento de los niños más pobres de entre 7 y 12 años, para asegurar futuras generaciones de soldados y funcionarios de condición ciudadana y nacimiento itálico. Con ello se intentaba contrarrestar la decadencia demográfica y económica de Italia a causa de la concurrencia de las provincias vecinas y la creciente presión fiscal debida a la expansión del Imperio y las necesidades de la guerra que colocaban a la región, en el caso de Veleia, en un lugar secundario. Así aparecen el nombre del fundo y al menos dos propiedades colindantes; el uso del suelo, los establecimientos existentes, rediles, hornos, la localización topográfica en el distrito (pagus), y, en su caso, en el ámbito más restringido del vicus (las sumas asignadas y el orden de prelación entre las categorías de niños beneficiados pueden verse en la dirección de internet señalada al principio de esta nota); GIOVANNI PAPA, Note sulla "Tabula alimentaria di Veleia", Labeo, 40, 1994, 1, 59-72, con abundante bibliografía sobre la institución alimentaria, ANTONIO FERNÁNDEZ DE BUJÁN, Derecho Privado Romano, 8. ${ }^{a}$ ed., Madrid: Iustel, 2015, p. 203; véanse los trabajos de JOSÉ MARÍA BLANCH NOUGUÉs, entre los que destacan: Régimen jurídico de las fundaciones en Derecho Romano, Madrid: Dykinson, 2007, pp. 124 ss.; "Acerca de la organización administrativa de las fundaciones alimentarias públicas en Roma", en Hacia un Derecho Administrativo y Fiscal Romano, ANTOnio Fernández de Buján, G. GereZ-Kremer, Belén Malavé Osuna, (coeds.), Madrid Dykinson, 2011, 209-226; José MARÍA BlANCH NouguÉs, "Observaciones acerca de la Tabula de Veleia", Revista de Derecho Romano (RGDR), www.iustel.com 2014 y el mismo autor "Acerca de las obligatones praediorum en la Tabula de Veleia"en Hacia un Derecho Administrativo, Fiscal y Medioambiental Romano, III, cit. 
existentes, rediles, hornos, la localización topográfica en el distrito (pagus), y, en su caso, en el ámbito más restringido del vicus; las cantidades asignadas y el orden de prelación entre las categorías de niños beneficiados.

Concretamente, la Tabula veleiana parece atestiguar la existencia de algunos pagi pertenecientes tanto al territorio de Veleia como al de otra ciudad, lo que confirmaría la interpretación de la historia del pago como algo continuo y que evoluciona en el tiempo. Según Schulten, la pertenencia de un mismo pago al territorio de dos comunidades limítrofes sería la prueba inequívoca de su origen prerromano. Sin embargo, una nueva interpretación considera que pudo deberse a un error del incisor que escribía en la tabla ${ }^{32}$.

En otro fragmento, no perteneciente a la Tabula alimentaria de Veleia pero seguramente relacionado con ella, aparece esculpida la palabra pagi aislada en el centro de una línea, lo que podría significar que se tratara de un documento fiscal del archivo de Veleia con un elenco de fundi, ordenado pagus por pagus ${ }^{33}$. Tarpin señala que lo confirmaría el hecho de que, en la Tabula alimentaria, los pagi son indicados como pago s(upra) s(cripto). El elenco de fundos sujetos a la institución alimentaria reagruparía, por comodidad, diversos fundi de un mismo pagus. Igualmente, otros documentos, referidos por el mismo autor, atestiguarían que el pagus sería una subdivisión oficial de la ciudad en la cual eran inscritas las propiedades fundiarias ${ }^{34}$.

\section{LA LEX RIVI HIBERIENSIS}

Plasmada en el conocido como Bronce de Agón (por ser ese el lugar de su hallazgo), dicha inscripción proporciona información sobre el funcionamiento de una comunidad de regantes en época adrianea, en el territorio del conventus caesaraugustano. Es conocida como lex rivi Hiberiensis por aparecer, al comienzo de la misma, las palabras "Hiberus capitonianus", seguramente en referencia a un canal principal que tomaba sus aguas del Hiberus. La lex ha facilitado información muy valiosa sobre el uso administrativo y práctico de esa unidad territorial que son los pagi. Por ejemplo, que los pagi pueden pertenecer a distintas ciudades con estatuto jurídico diferente, como se desprende del principio de la

32 Las cuestiones que plantea el estudio de la tabula sobre la pertenencia de terrenos comprendidos en el territorio de dos o más pagi, y de estos a comunidades diferentes, pueden examinarse en FEDERICO SANTANGELO, "Confini di città e confini di pagi nell'Italia romana", en Gli statuti municipali, cit., pp. 616-626.

33 Nicola CRINITI, La tabula alimentaria de Veleia, cit., fig. 13. MiCHEL TARPIN, "A cosa serve un pagus?" cit., 4.

34 Véanse los ejemplos y la bibliografía en Michel TARPIN, "A cosa serve un pagus?" cit., p. 4 notas 15 y 16 . 
inscripción $n_{i}$ el funcionamiento de dichos entes administrativos, y la existencia de magistrados con competencias administrativas, religiosas y sancionadoras ${ }^{35}$.

En el bronce se señalan los turnos de riego de dichas comunidades y el periodo (junio-julio) en que la acequia quedaba seca para su limpieza y reparación. También se alude a las contribuciones que los regantes debían satisfacer para el mantenimiento de la obra, así como a las sanciones por el incumplimiento de las disposiciones de uso. Se cita como órgano de gobierno el concilium paganorum y la intervención de los magistrados correspondientes. Además se menciona el lugar donde tuvieron lugar las reuniones para dirimir los asuntos concernientes a la administración del canal. Otra información que aporta esta inscripción es que la acequia discurría por los límites de la Colonia Caesaraugusta (Zaragoza) y del Municipium Cascantum.

La mención a tres pagos distintos certificaría que, dentro de las unidades superiores que fueron los municipios o las colonias, esta entidad territorial menor (el pago) era el núcleo básico para la ordenación administrativa de los pobladores dispersos por el amplio territorio rural. Poco se sabe de los pagos y de sus habitantes los paganos, pero todo indica que no eran unos núcleos de población compactos ${ }^{36}$; más bien eran áreas extensas, que tendrían como referencia una pequeña aglomeración urbana que funcionaría como centro rector de ese territorio y donde debieron residir sus instituciones, como el "Consejo de los paganos" citado en el bronce ${ }^{37}$.

\section{LA SENTENCIA JUDICIAL DEL 193 D.C.}

El decreto de L. Novius Rufus, plasmado en una tabla de madera que no ha llegado a nosotros (pero que debió pertenecer a la colección privada de Antonio Agustín, arzobispo de Tarragona en el siglo XVI) ${ }^{38}$, contenía la plasmación

35 Siguiendo a FRANCISCO BeLTRÁN LLORIS, "Irrigación y organización del territorio en la antigua Cascantum y el testimonio de la lex rivi Hiberiensis", en Navarra en la Antigüiedad: propuesta de actualización. Pamplona, ANDreu, J., (ed.), 2006, 230 ss.; ARMANDO TORRENT, "Los magistri pagi de la Lex rivi Hiberiensis: naturaleza y funciones", RIDROM, 2013; vid. sobre este tema, María Lourdes Martínez de Morentin, "Aproximación al régimen jurídico de una comunidad de regantes. El bronce de Agón" en Hacia un derecho administrativo, fiscal y medioambiental romano, III, cit., 323-349, con fuentes y bibliografía actual.

JuAn Francisco RodríGuez Neila, aunque sobre los pagi de la Bética, "Ciudad y territorio en la provincia romana de la Bética", Florentia Iliberritana: Revista de Estudios de la Antigüedad clásica, 4-5, 1993-1994, pp. 445-484.

37 PATRICK Le RouX, Le "pagus" dans la Peninsule Ibérique, en CHIRON, 39, 2009.

38 MARC MAYER, "Antonio Agustín entre política y humanismo: reflexiones sobre su aportación a la Epigrafía", en J. M. MAESTRE et al. (eds.), Humanismo y pervivencia del mundo clásico. Homenaje al profesor Antonio Fontán, III. 1, Alcañiz-Madrid: Instituto de Estudios HumanísticosCSIC, 2002, pp. 359-364 y nota 50. 
de un litigio entre unos compagani rivi lavarensis y una tal Valeria Faventina en el territorio de la Tarraconense. El conflicto, que no sabemos en qué consistía por lo fragmentario de la tabla, según el parecer de la doctrina mayoritaria, fue fallado a favor de la demandante, quizá una gran propietaria, frente a la invasión de sus territorios por parte de los aldeanos del lugar ${ }^{39}$. Si fue una cuestión sobre límites de fundos o una cuestión sobre la inmunidad para hacer frente a las cargas comunes de los pagani, no puede determinarse. Si se tratase de lo primero, según Álvaro D'Ors, tal vez pudo interponerse un interdicto restitutorio o una actio divisoria ${ }^{40}$. No puede descartarse, sin embargo, que se tratase de un litigio entre una comunidad de regantes y una propietaria ${ }^{41}$.

El epígrafe es la copia literal de una sentencia dictada por el gobernador de la provincia, Lucius Novius Rufus, en el año 193. En marzo del mismo año, poco después de haberse fallado esta sentencia, murió el emperador Pertinax, estallando a continuación la larga guerra civil que acabaría con la entronización de Septimio Severo. Como solía hacerse, el gobernador de la Tarraconense pidió previo parecer a su consilium.

El documento, que ha sido examinado en otro lugar ${ }^{42}$, nos interesa en esta sede en cuanto a que menciona unos compagani, lo que sin duda hace referencia a las estructuras rurales que son objeto de nuestra atención. Quizá estaríamos ante un probable ejemplo de la permanencia de la propiedad comunal, base económica de las estructuras sociales indígenas prerromanas que seguían siendo predominantes en la Hispania no romanizada. En este sentido, pudo tratarse de un conflicto social producido en Hispania, hacia mediados del siglo II, en el marco de la crisis del régimen esclavista, de la decadencia de las ciudades, del crecimiento del latifundio y de la explotación de los campesinos por parte de los grandes propietarios. El personaje que aparece en el pleito, Valeria Faventina, sería uno de esos terratenientes ${ }_{i}$ los compagani rivi larensis (o lavarensis), una comunidad de campesinos libres basada en la propiedad colectiva de la tierra.

El hecho de que las partes afectadas acudieran al gobernador y no a las autoridades de su municipio podría deberse a la gravedad de la disputa, que excedería de la jurisdicción de los magistrados municipales, o bien a la pertenencia de las partes a diferentes comunidades cívicas (como en el caso de la lex rivi Hiberiensis), pues no es fácil precisar la ubicación del rivus Larensis que aparece en el documento, que quizá fuera un canal de riego.

39 Vid. Jordi Pons, "Propiedad privada de la tierra y comunidades campesinas pirenaicas. Análisis de una sentencia judicial del año 193", Memorias de Historia Antigua, III, 197, 111 124.

40 Álvaro D'Ors, Epigrafía Jurídica de la España Romana (EJER), Madrid, 1953, 365.

41 Véanse las diferentes opiniones mantenidas al respecto en MARía LOURDES MARTíNEZ DE MOREnTIN, "El decreto de L. Novius Rufus", RGDR, 2016 (en prensa).

42 María Lourdes Martínez de Morentin, "El decreto de L. Novius Rufus", RGDR, 26, 2016 (en prensa). 
Hablar de compagani sugiere siempre la idea de una comunidad de campesinos de fuertes rasgos colectivos o comunales. En este supuesto, los compagani rivi Larensis serían una de las comunidades de campesinos, típica de los pobladores de las regiones pirenaicas durante esa época. En opinión de Pons, estas comunidades seminómadas, de estructura gentilicia, con dominio colectivo de la tierra, debieron escapar fácilmente a una romanización profunda, conservando su estructura social y económica en la Hispania romana, hasta los años de la decadencia del Imperio, quizá facilitando el proceso de feudalización que se produjo a continuación ${ }^{43}$.

\section{EL FRAGMENTO DE ULPIANO}

La función obvia del pagus es de naturaleza fiscal y censitaria, como recuerda Ulpiano en D. 50, 15, 4 (de censibus) $)^{44}$ :

Forma censuali cavetur, ut agri sic in censum referantur, nomen fundi cuisque et in qua civitate et in quo pago sit et quos duos vicinos proximos babeat et id arvum, quod in decem annos proximos satum erit, quot ingerum sit: vinea quot vites babeat: olivae quot iugerum et quot arbores babeant: pratum quod intra decem annos proximos sectum erit, quot iugerum: pascua quot iugerum esse videantur: idem silvae caeduae. Omnia ipse qui defert aestimet (Respecto a la forma de la declaración del censo se dispone, que los campos sean relacionados en el censo de este modo, el nombre de cada fundo, y en qué ciudad, y en qué pago se ha1le, y cuáles sean los dos vecinos próximos que tiene, y de cuántas yugadas sea la tierra labrantía que en los diez años próximos se hubiere sembrado; la viña, cuántas vides tenga $a_{i}$ el olivar, cuántas yugadas y cuántos árboles tenga; de cuántas yugadas sea el prado que haya sido segado dentro de los diez años anteriores; de cuántas yugadas parezcan ser las tierras de pastos; asimismo los bosques tallares; y estímelo todo el que hace la declaración).

Ulpiano, al señalar de qué modo ha de hacerse el censo y establecer que los campos sean relacionados siguiendo un orden que refiere el nombre de cada fundo, la ciudad en que se encuentran, el pago en que se hallan, los dos vecinos más próximos, etc., está reconociendo unas realidades rurales, los pagi, que facilitarán la posterior contribución para hacer frente a las necesidades del Estado en función de las riquezas y beneficios obtenidos por los particulares.

La doctrina considera que este pasaje, sobre la declaración del censo, es confirmado en diversos documentos, como por ejemplo en el llamado Bronce de

43 JORDI PONS, "Propiedad privada de la tierra y comunidades campesinas pirenaicas. Análisis de una sentencia judicial del año 193", p. 117.

44 UlPiANO escribió esta obra en el año 211, siendo emperador Antonino Caracalla (O LENEL, Palingenesia, 2, reimpresión Leipzig, 1889, p. 1247). 
Bonanza, de edad augustea, descubierto en España ${ }^{45}$, relativo a un contrato de compraventa de un fundo, en el que se sigue la fórmula ulpianea transcrita, de precisar y concretar las características y particularidades del fundo en cuestión (fundus Baianus, qui est in agro qui Veneriensis vovatur, pago Olbensi. Ad fines fundo dixit L(ucius) Baianus (el propietario) L(ucium) Titium et C(aium) Seium et populum (...)).

Hay testimonios de la utilización del pagus con fines fiscales en el siglo IV d.C., en la llamada Tabula de Trinitapoli ${ }^{46}$. En ella aparece un praepositus pagi $i^{47}$, como responsable de la transmisión de la información fiscal al tabularium ${ }^{48}$ de la ciudad ${ }_{\text {i }}$ aunque no se sabe nada sobre su designación, probablemente fue el precedente de los magistri pagi. De estos sí se sabe que debieron ser elegidos y estarían perfectamente informados de las extensiones de los campos y sus propietarios, del valor de sus tierras, $y$, por tanto, de las posibilidades de cada pagani para hacer frente a sus cargas y obligaciones.

Señala TARPIN ${ }^{49}$ que el número de pagi y la superficie media de un pagus son datos casi desconocidos pero que seguramente estarían sujetos a importantes variaciones. Sisani ${ }^{50}$, basándose en documentos epigráficos, propone una superficie media en torno a los 20 a $25 \mathrm{~km}$ cuadrados, pero refiere que también hubo pagi con superficies mayores ${ }^{51}$. Por otra parte, no se podría asegurar si toda la tierra del pagus estaría censada, o solo la tierra privada, o la tierra cultivada, o la usada como pasto (pascua). Respecto al número de pagi, no puede afirmarse la existencia de un número fijo por ciudad, sino que dependería de las dimensiones de la misma y la naturaleza de su territorio $;$ así se observa la existencia de entre cinco y diecisiete por ciudad, e incluso ninguno ${ }^{52}$.

45 Publicado por primera vez por Hübner en 1869. Vid. CIL, II, 5042=II, 5406=AE, 2000, 66-67. Sobre el mismo, vid. Juan Antonio Bueno DelGado, "El bronce de Bonanza", Anuario de la facultad de Derecho de la Universidad de Alcalá (AFDUA), 2004, pp.154-165. Andrea Giardina y Francesco Grelle, "La tavola di Trinitapoli", MEFra, 95, 1983, pp. 249-303.

48 Sobre la figura del tabularius, vid. ANTONIO FERNÁNDEZ DE BuJÁN, "Testigos y documentos en la práctica negocial y judicial romana", Revista Jurídica de la Universidad Autónoma de Madrid (RJUAM), 12, 2005, p. 125. La actuación de los tabularii se desarrollaba básicamente en el ámbito de la contabilidad, la percepción de impuestos y los archivos públicos, de ahí que se considerara su cargo dentro de los officia publica de las ciudades, no obstante la limitación de sus facultades de autenticadores en relación con la fides publica. Vid. también G. I. LuZZATTO, Tabularius NNDI, Torino, XVIII, 1971, pp. 1012 ss. Michel TARPIN, "A cosa serve un pagus?", cit., p. 4.

50 SimOne SiSANI. In pagis forisque et conciliabulis. cit., pp. 551-780.

51 Michel TARPIN, Vici et pagi dans l'Occident romain, cit., 201.

52 SimOne SiSANI, In pagis forisque et conciliabulis, cit., pp. 603. Puede confrontarse en el CIL XIII, CIL IX, y en el AE 1969/70. 


\section{SICULO FLACCO}

Si bien Siculo Flacco ${ }^{53}$ escribió seguramente en el siglo IV, a tenor de la mención en su obra del pergamino, además del papiro y el bronce, entre los materiales en los que se hacía la forma ${ }^{54}$, reflejaría la práctica de una realidad existente ya en época clásica. En su obra de condicionibus trata sobre los pagi y su delimitación.

Forma, en el lenguaje de los agrimensores, se refiere a un documento oficial de la ordenación territorial, y también a mapa de trabajo para el agrimensor en el que este trazaba todos los elementos del paisaje que le podían ayudar en su labor técnica, no es lo mismo que el plano catastral, que es simplemente un plano de la zona centuriada (ager divisus et adsignatus) confeccionado con fines fiscales ${ }^{55}$.

Como unidad territorial con función censitaria, el pagus tenía límites o fines fijados por los magistri pagi en la lustratio.

Los magistri pagorum ${ }^{56}$ eran los jefes del pagus; elegidos anualmente, su número variaba según el pagus, pero por lo general eran dos. Se encargaban de proteger los lugares sagrados del pagus y desempeñaban una serie de funciones en relación con las viae vicinales y con los munera que correspondía cumplir para con el municipio o la colonia a cuyo territorio pertenecían. Tenían la carga de la lustratio ${ }^{57}$ que fijaría el confín del pagus. Así viene reflejado por Siculo Flacco en su tratado (de condicionibus agrorum):

Sed et pagi saepe significanter finiuntur de quibus non puto quaestionem futuram, quorum territorium ipsi pagi sint, sed quatemus territoria. Quod tamen intellegi potest vel ex boc, magistri pagorum quod pagos lustrare soliti sunt, uti trabamus quatenus lustrarent (Pero también los pagi son delimitados, a menudo, de una manera significativa. Sobre ellos, creo

53 Aunque es difícil dar una fecha, parece que su vida transcurrió entre los años 292 y el 313.

54 Siculo Flacco, de condicionibus agrorum (obra consultada en la $1^{\text {a }}$ edición crítica del Corpus Agrimensorum Romanorum (CAR) en 1848 a cargo de LACHMAN (La.) y THULIN (Th.): Ergo agrorum divisorum, qui institutis limitibus divisi sunt, formae varias apellationes accippiunt quidam in arboreis tabulis, alii in aenis, alii membranis scripserunt (...), edición y traducción de MARÍA José CASTILlo PASCUAL, Opuscula agrimensorum veterum, Logroño, Universidad de la Rioja, 2011, xviii y 104. El papiro fue el soporte de los documentos administrativos hasta que en el siglo IV d.C. fue sustituido por el pergamino.

55 María José Castillo Pascual, Glosario, Opuscula Agrimensorum veterum, p. 152.

56 Michel TARPIN, Vici et pagi dans l'Occident romain, cit., pp. 285 ss. Hoy son mejor conocidas sus funciones gracias a la lex rivi Hiberiensis; ARMANDO TORRENT, "Los magistri pagi de la Lex rivi Hiberiensis: naturaleza y funciones", cit.

57 Siculo Flacco, De condicionum agrorum, 164 La., 129 Th., en MARÍA José CASTILlo PASCual, Opuscula agrimensorum veterum, cit., pp. 123 y 130. Vid. también Fremiot HERNÁNDEZ GONZÁLEZ, Un ensayo de clasificación del vocabulario técnico de los gromatici veteres del CAR, Actas del X Congreso de la SEEC, Madrid, 2001, pp.121-128; el mismo autor "Sobre el vocabulario técnico de la agrimensura" en Nova et vetera. Nuevos borizontes de la Filología latina, Madrid, 2002, pp.103-218. 
yo, que no se preguntará de qué territorios son los pagi mismos, sino cuál es la amplitud de estos territorios. Sin embargo, esto puede averiguarse, por ejemplo, por lo siguiente: puesto que los magistri pagorum han solido purificar los pagi, de manera que nos fijamos hasta donde purifican).

Así, las fronteras de un pagus, y por tanto la extensión de su territorio, se podían fijar una vez conocidos los límites de la lustratio. Esta ceremonia se llevaba a cabo durante las Paganalia, fiestas particulares del pagus, sufragadas por los pagani, cuya finalidad era la purificación del cantón ${ }^{58}$. Un pasaje de Ovidio (Fast. 1, 669-70) y la tessera paganica de Tolentinum ${ }^{59}$ confirman la normalidad del ritual de la lustratio.

El problema en materia de derecho del suelo y de fiscalidad no trataría tanto sobre el conocimiento de a qué ciudad pertenecía un pagus, lo que probablemente era obvio para todos y además debía estar registrado en el archivo de la colonia o del municipio, como relata Siculo Flacco ${ }^{60}$, sino sobre cuál era el territorio de ese pagus concreto. Este sería el factor a tener en cuenta cuando se estuviera reclamando al pagus el pago o la realización colectiva de un servicio ${ }^{61}$. Así: Si vero de ipsis pagis quaestionem quis moveat, amplae rei negotium movetur (...) (Pero si alguien origina una controversia por los pagi mismos, se promoverá un asunto de importancia $(. .)$.$) .$

\section{LA RELACIÓN ENTRE PAGI Y CATASTRO}

La etimología de la palabra pagus hace referencia a un lugar cuyos límites están fijados en la tierra o cuya frontera es natural; pero también a un territorio rural delimitado por hitos o mojones. Catasta, a estrado, reconocimiento del

58 María José Castillo Pascual, Opuscula agrimensorum veterum, cit., p. 139; Dion. Hal., Ant., $4,115,4$. El origen de esta fiesta hay que buscarlo en la época en que los ciudadanos romanos estaban divididos en montani y pagani (vid. VARRÓN, De ling. Lat.). Sobre estas operaciones vid. MARÍA JOSÉ CASTILLO PASCUAL, Espacio en orden: El modelo gromático romano de ordenación del territorio, Logroño, La Rioja, 2011.

59 En el paganicum podrían estar expuestas las tesserae paganae; sobre su uso, la escasez de documentos no permite más que frágiles hipótesis; vid. JOAQUín L. GÓMEZ PANTOJA, "No siempre la inscripción es lo más importante. Un bronce de Gallur (Zaragoza) y las tesserae pagi", en Hispania y la epigrafía romana. Cuatro perspectivas, JuAn FranCisCo RodríGueZ NeILA, (dir.), Faenza, 2009, 105, nota 73.

60 Siculo Flacco, de condicionibus agrorum: En efecto, a menudo encontramos en los archivos públicos descritos los territorios de una manera clara, pues por los nombres conocidos de algunos lugares comienzan a circundarse los territorios (...), MARÍA JOSÉ CASTILLO PASCUAL, Opuscula agrimensorum veterum, cit., 121.

61 TARPIN, "A cosa serve un pagus?" cit., p. 6. 
terreno $^{62}$; y catastro ${ }^{63}$, a capitastrum, de caput capitis, cabeza, y en este sentido, censo y padrón estadístico de las fincas rústicas y urbanas con fines fiscales ${ }^{64}$.

A efectos de la fiscalidad se requeriría la identificación del fundus y su posición. Cuando no se conociera un nombre o un número de calle, lo más sencillo sería aportar los datos que facilitasen su identificación ${ }^{65}$. La solución para localizar una posesión, en el mundo romano, fue el uso de la centuriación ${ }^{66}$. Gracias a este sistema, técnicamente perfecto, claro y simple, se podía saber la persona que tenía en arriendo un terreno determinado en un lugar concreto. La centuriación permitía la organización de un catastro perfecto. Por ejemplo, bastaría decir que el fundus constaba de veinte ingera en la centuria citra cardinem XXIV, decumanus dexter III, para poder saber exactamente dónde se encontraba ${ }^{67}$. Se necesitaría solo actualizar los documentos anexos a la forma, el documento catastral administrativo, y asegurarse de la permanencia de los campos ${ }^{68}$.

Como afirma Tarpin ${ }^{69}$, son raros los lugares en los que fue posible conservar la forma cuadrada de la centuriación durante siglos. Lo normal debió ser que los possessores fundi y los campesinos prefirieran limitar un campo con un río, una hilera de árboles o relieves naturales. Podría suceder también que la centuriación no siempre fuera perenne y resultase deformada con transacciones posteriores realizadas por los ocupantes de las tierras asignadas. Por otra

62 Dictionnaire étymologique de la langue latine, A. ERNOUT et A. MEILLET, Paris, 1967.

63 Diccionario de la lengua española, RAE.

64 A esta función catastral del pagus se refería MARía LuISA CORTIJO CerEZO, El pagus en la administración territorial romana. Los pagi de la Bética, cit., p. 105.

65 Michel TARPIN, "Strutture territoriali romane: tra complessità ed efficienza", cit., p. 201.

66 Luigi CAPOGROSSI COLOGNESE, "Le forme gromatiche del territorio e vari regimi giuridici dell'ager Romanus e dell'ager colonicus. Il complesso mosaico della romanizzazione italica", cit., p. 582; M. TALAMANCA, Istituzioni di diritto romano, Milano, Giuffrè, 1990, p. 395: "La diviso et adsignatio era un procedimento di 'privatizzazione' dell'ager publicus, disposto per legge o plebiscito. Esso presupponeva la centuriatio del territorio da dividire et adsignare, e cioè una parcellizzazione che, acompagnata da una serie di riti carichi di valori e di simboli religiosi, avveniva tracciando un reticolo di rette parallele a due assi cartesiani: le parcelle fondiare ottenute potevano essere oggetto di una semplice assegnazione viritana, fatta a singoli patresfamilias [... ] più spesso, invece, la centuriatio $e$ la assegnazione venivano fatte in occasione della fondazione di una colonia civium romanorum, nel qual caso gli assi cartesiani di cui si è detto costituivano il cardo $e$ il decumanus maximus, ed il loro punto d'incontro il foro della nuova città. Si procedeva alla centuriatio anche nel caso di fondazione di una colonia Latina, in cui gli assegnatari non conseguivano, ovviamente, il dominium ex iure quiritium, ed anche, nelle province, per la distibuzione di agri vectigales o provinciales (connessa o meno alla fondazione di nuove città), dove gli assegnatari ottenevano soltanto la c.d. proprietà vettigalista o provinciale".

67 MiChel TARPIN, "Strutture territoriali romane: tra complessità ed efficienza", cit., p. 201.

68 María José Castillo Pascual, Opuscula Agrimensorum veterum. Vid. en Glosario, los conceptos: fundus, iugerum, cardo, decumanum, centuria, etc. También FREMIOT HERNÁNDEZ GONZÁLEZ, Un ensayo de clasificación del vocabulario técnico de los gromatici veteres del CAR, cit., 121-128 y "Sobre el vocabulario técnico de la agrimensura"cit., 103-218.

69 Michel TARPIN, "Strutture territoriali romane: tra complessità ed efficienza", cit., p. 201. 
parte, en realidad, la mayor parte de la tierra no estaba dividida en centurias y por tanto dividida y asignada. Cuando la centuriación no se pudiera incluir en el paisaje, el fundus podía describirse recurriendo a puntos naturales notables. Por ejemplo: "A monticellum babet. Post montem non transit ad collem (...). Habet ad pedem aqus vivas duas, et sub se flumen".

Los gromáticos señalaban la diferencia existente entre una división "per centurias" y una división "perprofessiones". Este doble sistema obedecería, por una parte, a una división arbitraria, determinatio, y por otra, a una definitio basada en la particularidad o geografía del paisaje, pero la relación entre centuriación y localización per professiones sigue siendo un enigma ${ }^{70}$.

El census, y por tanto la fiscalidad, estaban ligados o vinculados a la declaración hecha por el possessor fundi en el momento del mismo; la forma de los gromáticos servía sobre todo en caso de controversia a propósito de límites (fines $)^{71}$. Para la imposición y cobro de las tasas se necesitaría conocer la localización del fundus, en qué ciudad se encontraba y cuál era su renta o cuáles eran sus beneficios ${ }^{72}$.

La declaración de bienes hecha por el possessor fundi era muy útil debido a la complejidad de los estatutos locales en una ciudad; si se trataba de colonos o antiguos possessores, si de ager publicus, prados comunes, bosques, tierra de los santuarios, etc. Se comprendería, por tanto, que el uso del pagus, como estructura territorial elemental a escala humana, fuera preferido al sistema geométrico rígido de las centuriaciones (más preciso pero más complejo), pues al tener límites definidos (gracias a la lustratio, tal y como señala Siculo Flacco) permitiría obtener información directa para poder hacer frente a las cargas y obligaciones cotidianas.

70 MiCHEL TARPIN, "Strutture territoriali romane: tra complessità ed efficienza", cit., p. 201.

71 HiginO, De condicionibus agrorum, Th. 74.4 (La. 114.12): "Siempre que haya tenido lugar entre vecinos este tipo de pleito, debe preguntarse a los agrimensores [...]". Vid. LAURETTA MAGANZANI, "Arpenter la terre pour le procès: la consultation technique en droit romain", RIDA, 53, 2006, 283-29; LAURETTA MAGANZANI, Gli agrimensori nel processo privato romano, Roma, 1997, 99 ss. con abundante bibliografía.

72 Según el sistema de Ulpiano ya descrito en D. 50, 15, 4. Para Higino, De condicionibus agrorum, Th. 74.4 (La. 114.12): "La controversia del derecho del territorio se entabla siempre que se litiga por el tributo exigido por una propiedad, cuando una de las partes afirma que esta se encuentra dentro de la frontera de su territorio y la otra, por el contrario, afirma lo mismo [...]. En efecto, a menudo vemos en los documentos oficiales claramente descritos los territorios, así como desde la pequeña colina que se llama así hasta aquel río y a través de aquel río hasta aquel arroyo o aquel camino, y a través de aquella vía hasta el pie de aquel monte, este lugar es llamado así; y de allí a través de la cumbre de aquel monte hacia lo más alto y por lo más alto del monte, por las divisorias de agua, al lugar que es llamado así y desde allí hacia abajo, hasta aquel lugar, y de allí al cruce de caminos de aquel lugar, y de allí a través del monumento sepulcral de aquel hasta el lugar desde donde primeramente comenzó a trazarse la frontera $[\ldots]^{\prime \prime}$. 
Del estudio de las fuentes no se deduce que existiera contradicción entre pagus y centuriación, por lo que la estructura de la fiscalidad romana podría explicar la coexistencia de ambas situaciones. Ciertamente habría una diferencia fundamental entre el vectigal, impuesto universal -recaudado por la ciudad sobre los terrenos públicos adjudicados por centuriación- ${ }^{73}$, y las otras tasas, como el tributum o la annona, apoyadas sobre la professio ${ }^{74}$ de los propietarios o possessores. MOATTI ${ }^{75}$ advierte la diferencia entre un modo de registro externo, hecho por el geómetra ${ }^{76}$ (centuriación), destinado sobre todo a la percepción del vectigal, y la declaración fiscal, tipo tabula alimentaria, basada en la real posibilidad de los fundos de contribuir a las cargas.

Para Higino ${ }^{77}$, en la forma aparecen registrados los fundi por professiones de los antiguos propietarios o possessores. Pero también los nuevos possessores, establecidos en la parte centuriada ${ }^{78}$, habrían de declarar su patrimonio según el procedimeinto descrito por Ulpiano, es decir, pagus por pagus. Para Tarpin ${ }^{79}$, tabula alimentaria y catastro no serían documentos contradictorios sino complementarios.

Desde el punto de vista del census, el pagus presentaría la ventaja de la perennidad territorial ${ }^{80}$, frente a la parcela atribuida al colonus, sujeta a reducción o ampliación como consecuencia de las relaciones entre los propietarios. Además, el pagus serviría también de marco para afrontar las diversas obligaciones locales o cívicas que surgieran en relación con los caminos secundarios, ríos, canales y bosques, y todas las cosas ligadas a la naturaleza del terreno y al

73 MaRio TAlamanCA, Istituzioni di diritto romano, cit., 397.

74 En este contexto, professio censualis hace referencia a la declaración hecha por el propietario ante el censor durante el censo, de la ubicación de su parcela (ciudad, pagus y parcelas colindantes) y de la superficie cultivada (número de cepas, yugadas de olivares, árboles, extensión de las zonas de pastos, etc.; vid. D. 50,15,4). Sobre el censo, José GuILLÉN, Urbs Roma, II La vida pública, Salamanca, Ed. Sígueme, 1978, 60-63, 186 ss.; Tito Liv., 2, 24, y 4, 8, 2-7; GEMA TORIBIO POLO, "Finalidad probatoria de la professsio censualis", RIDROM, 2012.

75 C. MOATTI, Archives et partage de la terre dans le monde romain (IIe siècle avant - Ier siècle après J.C.), Rome, 1993.

76 Tipo catastro de Orange. Sobre el mismo, vid. MiChel CHRISTOL, "Ressources des colonies, ressources de l'Etat" en Colons et colonies dans le monde romain, a cargo de $\mathrm{S}$. Demougin, J. Scheid, Rome, 2013, pp. 65-86.

77 HyGinO, de condicionibus agrorum, 74.4, Th. (114.12, La.).

78 Establecidos en el ager divisus et adsignatus, también llamado ager colonicus, ager limitatus, ager centuriatus; vid. Glosario, en MARÍA JOSÉ CASTILlO PASCUAL, Opuscula agrimensorum, cit.

79 Michel TARPIN, A cosa serve un pagus? cit. p. 8.

80 Según Félix-Georges De PaChtère, La table hypothécaire de Véléia, Paris, 1920, el pagus es un territorio natural con una pertenencia clara, apoyada sobre diversos elementos del relieve y la hidrografía, pero puede también corresponder al territorio de una comunidad integrada en una nueva ciudad. 
relieve, lo que requeriría conocer con precisión las posibilidades de cada uno de los possessores fundi ${ }^{81}$.

\section{PAGI Y OBLIGACIONES INTERNAS: MANTENIMIENTO DE VÍAS SECUNDARIAS, ABASTECIMIENTO DE AGUA, REPARACIÓN DE CANALES Y OTRAS CARGAS}

Como se ha mencionado anteriormente, dentro de cada pagus habría que hacer frente a ciertas cargas o responsabilidades.

\subsection{MANTENIMIENTO DE LOS CAMINOS SECUNDARIOS}

Siculo Flacco ${ }^{82}$, distinguiendo las vías que marcan el lindero, señala que la categoría de las mismas no es única ni la misma. Así, afirma que existen vías públicas que son construidas por el Estado y llevan los nombres de sus promotores, las controlan curatores y son construidas por adjudicatarios; a los propietarios se les exige periódicamente cierta suma por el mantenimiento de algunas; en cambio, las vías secundarias son construidas de otra manera, exigiendo su mantenimiento a los habitantes de los pagi:

Vicinales autem viae, (...) aliter muniuntur, per pagos, id est per magistros pagorum, qui opera a possessoribus ad eas tuendas exigere soliti sunt. Aut, ut comperimus, uni cuique possessori per singulos agros certa spatia assignantur, quae suis impensis tueantur (En cambio, las vías vecinales, que llegan hasta los campos desde las vías públicas y, a menudo, las mismas conducen a otras vías públicas, son construidas de distinta manera, por los pagi, es decir por los magistri pagorum, quienes tienen por costumbre exigir para mantener éstas, trabajos a los propietarios; o bien, como averiguamos, a cada propietario se han asignado por cada campo determinados tramos que mantienen a sus expensas).

Tarpin ${ }^{83}$ refiere un pequeño grupo de inscripciones de Concordia, con nombres de pagi e indicaciones sobre su longitud, que señalarían la obligación del pagus respecto del cuidado y mantenimiento de un segmento de camino, siguiendo un procedimiento que, al parecer, estuvo en vigor hasta el siglo XVIII. El lugar del hallazgo indica los caminos secundarios, confirmando el texto de Siculo Flacco. La longitud prevista es inferior a la dimensión del pagus, lo cual hace pensar que, o bien la responsabilidad colectiva era muy limitada, o las ins-

81 Michel TARPIN, A cosa serve un pagus? cit. p. 8.

82 Siculo Flacco, De condicionibus agrorum, Th. 110 (La. 146) en la traducción de MARÍA José CASTILlo PASCUAL, Opuscula agrimensorum veterum, cit., p. 89.

83 Las referencias en MiCHEL TARPIN, A cosa serve un pagus? cit., p. 9 
cripciones no recogían más que los trabajos relativos a un año concreto o a un trozo de camino, dañado o deteriorado, que habría que reparar.

\subsection{MANTENIMIENTO DE LAS CONDUCCIONES DE AGUA}

Otras obligaciones estarían relacionadas con el abastecimiento del agua a nivel local. En este sentido la lex rivi Hiberiensis ${ }^{84}$, ya mencionada, aporta interesante información.

Como se ha señalado en otro trabajo ${ }^{85}$, la ley, dada por un legado del emperador o un gobernador provincial ${ }^{86}$ en tiempos de Adriano a varios pagi ${ }^{87}$, fijaba las reglas de uso del agua a la comunidad de regantes, señalando que el mantenimiento de los canales y presas se realizase a cargo de los pagani. Si, como parece, cada paganus se encargaba de los trabajos, en correspondencia con su derecho al agua, la doctrina especializada ha supuesto la existencia de un documento preliminar fijando los días y las horas atribuidas a los diferentes fundos, según el modelo de la inscripción de Lamasba ${ }^{88}$, modelo confirmado, también, en otras fuentes ${ }^{89}$.

Según la lex rivi Hiberiensis, los magistri pagi tenían la responsabilidad de hacer limpiar los canales a los pagani los cuales, en caso de inhibirse, serían multa$\operatorname{dos}^{90}$. Sin embargo, las decisiones en torno al mantenimiento de los canales

84 Vid. la editio princeps, FRANCISCO BELTRÁN LLORIS, "An irrigation decree from Roman Spain: the Lex rivi Hiberiensis", pp. 147-197.

85 Vid., María Lourdes Martínez de Morentin, "Aproximación al régimen jurídico de una comunidad de regantes: el bronce de Agón", cit., con bibliografía actualizada.

86 A favor de un legado jurídico, FRANCISCO BELTRÁN LLORIS, "El agua y las relaciones intercomunitarias en la Tarraconnese", cit, p. 33; D. NÖOR, "Prozessuales (und mehr) in der lex rivi Hiberiensis", ZSS 125, 2008, 108-187; a favor de la figura de un gobernador provincial, aunque con dudas, ROSA MeNTXACA, "Lex rivi Hiberiensis, derecho de asociación y gobernador provincial", cit., 46 y PATRICK Le ROUX, "Le pagus dans la peninsule Iberique", cit., 21.

87 La discusión a propósito del número de pagi en MiCHEL TARPIN, "La lex rivi Hiberiensis: une restitution de l'incipit", en Zeitschrift für Papyrologie und Epigrapbik, 192, 2014, pp. 265-272 (dos pagi y un castellum), FRANCISCO BELTRÁN LLORIS, "An irrigation decree from Roman Spain: the Lex rivi Hiberiensis" cit., 147-197 (tres pagi), PATRICK Le ROUX, "Le pagus dans la péninsule Iberique", cit., 19-44 (dos pagi).

88 Vid. FÉLIX-GeOrges De PACHTÈre, "Le réglament d'irrigation de Lamasba", Mel. d'Archéologie et d'bistoire, 28, 1908, 373-405, disponible en: www.persee.fr/web/revues/home/prescript/ article/mefr_JEAN BIREBENT, Aquae Romanae. Recherches d'bydraulique romaine dans l'Est algérien, Algérie 1962, 385-406; H. PAVIS D'ESCURAC, "Irrigation et la vie paysanne dans l'Afrique du Nord", en Ktéma 5, 1980, 177-191; BRENT SHAW, "Lamasba: an ancient irrigation community", en Antiquités Africaines 18, 1982, 65-102; A. WILSON, Water Management and Usage in Roman North Africa. A social and technological study, Ph. D. thesis (Oxford 1997).

89 Las referencias en MiCHEL TARPIN, "A cosa serve un pagus?" cit., p. 10.

90 Vid. la editio princeps; I. 9-15: et si qui, arbitratu eorum aut eius qui operis prae/erit, operas non praestiterit aliutue quid <quod $>$ ab eo/ imperatum denuntiatumue erit detractauerit / moramue quo setius fiat fecerit 
no serían dictadas por los magistrados mismos, sino "ex maioris partis paganorum sententia dum proportione quantum quique aquae ius babent"(lrH, I. 6-8), en virtud de la decisión tomada por la mayoría de los pagani según la proporción de agua que utilizasen, procedimiento similar al señalado por Siculo Flacco en relación con la reparación de los caminos o vías secundarias (Aut, ut comperimus, uni cuique possessori per singulos agros certa spatia assignantur, quae suis impensis tueantur) ${ }^{91}$.

Los possessores pagi serían registrados, pagus por pagus, en el album de la ciudad, y probablemente habría una copia en el paganicum, lugar de reunión del pagus $^{92}$. En caso de comisión de una falta por parte de un magister, los pagani (consilium pagani) podrían sancionarlo con una multa que iría a parar a una caja común, y se destinaría, tal vez, para pagar los trabajos no realizados por su negligencia en hacer cumplir dicha tarea.

El papel del pagus en el control del agua debió ser antiguo, pues se encuentra en un pasaje de Festo ${ }^{93}$, aludiendo, quizá, a una ley republicana, y en otras inscripciones de la misma época. Igualmente se manifiesta la importancia que tuvo en el mantenimiento de las obras públicas, tal y como revela la inscripción de Vsconium ${ }^{94}$

Algunos autores, al aludir a los conflictos sobre el agua que, seguramente, se suscitarían entre compagani, citan el decreto de Novio Rufo ${ }^{95}$, examinado anteriormente, pero existen dudas razonables sobre cuál fuera, realmente, el propósito del mismo.

\subsection{OTRAS CARGAS}

Además de las obligaciones señaladas, necesarias para el funcionamiento del pagus, habría también otras cargas impuestas por el Estado a las ciudades no inmunes; por ejemplo, la de contribuir al sustento del soldado y del magistrado y su escolta cuando estuvieran de paso. En este sentido, recuerda Siculo Flacco ${ }^{96}$ :

pecuniamue ad / diem non soluerit, tum quotiens commiserit to/ltiens in singula imperata magistris pagi (denarios) XXV $\mid d($ are $) d($ ebeto). Id omne magistri pagi in commune redigunto.

91 Siculo Flacco, de condicionibus agrorum Th,110 (= La.,146), en MARÍA José CastiLlo PASCUAL, Opuscula agrimensorum veterum, cit., p. 89.

92 Vid. con la $\operatorname{lrH}$, III. 2 mag(istris) pagi]? 1 publicanoue eorum in paganico sub praecone uen/dere liceto.

93 Festo, De verborum significatione, en BRUNS, Fontes Iuris romani antiqui editio sexta, Friburgo de Brigovia et Lipsiae, 1893.

94 Referida por MICHEL TARPIN, A cosa serve un pagus?, ob. et loc. cit.

95 Vid. Pons, J., "Propiedad privada de la tierra y comunidades campesinas pirenaicas. Análisis de una sentencia judicial del año 193" cit. Últimamente, MARÍA LOURDES MARTíNEZ DE MOrEnTIN, "El decreto de L. Novius Rufus", RGDR, 26, 2016 (en prensa), con un resumen de la bibliografía sobre el mismo.

96 Siculus Flaccus, de condicionibus agrorum, Th. 129 (La. 164) en MARÍA JOSÉ CastiLlo PASCUAL, Opuscula agrimensorum veterum, cit., p. 123. 
Nam et quotiens militi praetereunti aliive cui comitatui annona publica praestanda est, si ligna aut stramenta deportanda, quarendum quae civitates quibus pagis buius modi munera praebere solitate sint. (Y en efecto, siempre ha de prestarse la annona publica al soldado de paso y a la escolta; si ha de transportarse leña o paja, ha de averiguarse qué ciudades han solido cumplir los munera de esta manera, en qué pagi).

Siculo Flacco añade esta responsabilidad a la lustratio y a la delimitación del territorio pagano, lo que significaría una responsabilidad del magister pagi, que a la vez que cuidara la lustratio, debería reclamar a los possessores particulares una parte del suministro, para cubrir las necesidades del soldado o del magistrado y su escolta cuando estuvieran de paso, según las posibilidades de cada uno. Desgraciadamente, Siculo Flacco no dice nada del procedimiento por el que se fijaban las cantidades debidas por los possessores fundi de manera individual ${ }^{97}$. $\mathrm{Ni}$ se sabe tampoco si, en el caso de que uno de los possessores tuviera una inmunitas personal, transferible en el caso de nuevas adquisiciones, los otros pagani deberían pagar de más.

Aparte de las obligaciones o servidumbres mencionadas, un documento aislado parece demostrar la posibilidad de un pagus de determinar las reglas internas relativas a la caza ${ }^{98}$, sin necesidad de la intervención de un magister, y en relación a un tipo de bosque comunal utilizado por todos los pagani, previo pago.

\section{CONSIDERACIONES FINALES}

Pero, ¿qué finalidad tendría el pagus? La complejidad de la estructura administrativa romana es un hecho percibido por los investigadores, que intentan afrontar el estudio del territorio romano como una realidad material, como un sistema institucional o como un elemento de un sistema económico completo. En el momento actual de las investigaciones, se han realizado esfuerzos tendentes a unificar las distintas interpretaciones. Las centuriaciones, arqueológicamente identificadas, los textos técnicos de los gromáticos, los jurídicos, los literarios y los epigráficos han contribuido a ello. Aunque no se ha podido demostrar de modo absoluto que las estructuras territoriales fueran las mismas en todas

97 A diferencia de la Tabula alimentaria de Veleia, donde sí aparecían recogidas las cantidades debidas para hacer frente a los gastos de mantenimiento de cada uno de los niños y niñas pobres; vid. NicOla CRINITI, La tabula alimentaria de Veleia, Parma, 1991, disponible en: www.veleia.it y JOSÉ MARÍA BlANCH NOUGUÉS, "Acerca de las obligationes praediorum en la Tabula de Veleia", cit., 10.

98 Según TARPIN, se trataría de una normativa interna que no justificaría la intervención de un magistrado, al contrario de la lrH (MiCHEL TARPIN, "A cosa serve un pagus?", cit., nota 57$)$. 
las partes del Imperio, pues las condiciones materiales serían diferentes de un lugar a otro, sí puede hablarse de unas realidades administrativas llamadas pagus.

La documentación sobre los pagi es escasa, sin embargo, la lectura de algunos documentos epigráficos, de los gromáticos y varios pasjes del Digesto permiten precisar en algo su funcionamiento. Sobre todo se confirma su función censitaria y fiscal.

Teniendo en cuenta los diversos ocupantes de los pagi, de estatutos iguales o diferentes, y no todos ciudadanos de la ciudad a la que perteneciera el pagus, esta unidad territorial, coherente y delimitada, debió ser indispensable para las necesidades prácticas y para el funcionamiento del sistema fiscal de tipo romano, basado en la professio del contribuyente. Mientras que la centuriación era indispensable para proceder a la divisio y la adsignatio, para poder contribuir a las cargas, la observación del terreno, la historia local y sus características impresas en el paisaje, resultaba más eficaz.

Para los possessores fundi sería ventajoso registrarse como un propietario o possessor privilegiado o considerado fuera de la centuriación, porque desde el punto de vista territorial quedaba en el pagus. Sin embargo, falta información sobre la participación de los immunes en las obligaciones y cargas locales. El silencio de la lex rivi Hiberiensis y de los gromáticos podría dejar suponer que la immunitas no significaba la exención de los trabajos de interés común. De cualquier modo, el hecho de beneficiarse de la immunitas no les excluiría de la necesidad de ser censados regularmente.

El hecho de que los pagi constituyesen el marco para el censo de distintos fundi no significaría que tuviesen autonomía para la gestión de los diversos intereses locales, que quizá estuvieran bajo el control de la ciudad, como recuerda la lex rivi Hiberiensis ${ }^{99}$, que confirmaría la necesidad de acudir a la sede más próxima de la autoridad judicial de la ciudad en los casos conflictivos.

Que los pagi pudieran pertenecer a distintas comunidades cívicas aparece en la lista de la Tabula alimentaria de Veleia. También encontramos pagi, pertenecientes a distintas ciudades con estatuto jurídico diferente, utilizando conjuntamente un canal de riego, en la $\mathrm{lrH}$.

Que los pagi tenían magistraturas, que funcionaban con estructuras similares a las existentes en los municipios y ciudades, se atestigua en la $\operatorname{lr} H$ y en el tratado de Siculo Flacco. Los magistri pagi tenían funciones religiosas (paganalia), administrativas (atribución de cargas) y sancionadoras (cobro de multas dentro de un margen a aquellos que contravinieran el tenor de las disposiciones paganas).

Los pagani obligados a contribuir a las cargas serían, obviamente, no todos los habitantes, sino solo los possessores fundi a que se refiere Siculo Flacco. Ellos serían los únicos que tendrían la capacidad y la posibilidad legal de pagar, o de 
enviar esclavos o libertos para realizar los trabajos necesarios. Sin embargo, con base en los textos examinados, no es posible afirmar, ni tampoco negar, la obligación, para un propietario de pleno derecho, de contribuir a los trabajos comunes en relación con las vías secundarias o canales de agua. Esa quizá sería la razón por la que fue más sencillo hablar de paganus, pues con ese término se indicaba a todos aquellos que con un título u otro, desde el punto de vista jurídico, debían pagar por los trabajos. También es posible admitir que un gran propietario pudiera ser, en cuanto possessor, paganus en diversas ciudades. En todo caso, para esclarecer las cuestiones relativas a límites de fundos y atribución de propiedad, de cara a la contribución fiscal, sería necesaria la labor técnica de los agrimensores.

\section{BIBLIOGRAFÍA}

AA.VV., Gli statuti municipali, Pavía: IUSS Press, L. CAPOGROSsI COlOGneSI y E. GabBA (ed.), 2006.

AA.VV., Lex rivi biberiensis. Diritto e tecnica in una comunità di irrigazione della Spagana romana, Giornate di studio in ricordo G. Luraschi, Milano 2-3 julio 2012, L. MAGANZANI y Ch. BuzZaCHI (eds.), Nápoles: Jovene, 2014.

AlbuRquerque, Juan Miguel. "Concentración y ordenación urbanística del territorio romano: colonias, conventos y municipios de la Bética", Hacia un derecho administativo y fiscal romano, Madrid, 2011, pp. 77-113.

BeLtRÁn LlORIS, FRANCISCO. "An irrigation decree from Roman Spain: the Lex rivi Hiberiensis", JRS, 96, 2006, pp. 147-197, disponible en http://droitromain.upmfgrenoble.fr/

BELTRÁN LLORIS, FRANCISCO. "El agua y las relaciones intercomunitarias en la Tarraconense", Aquam perducendam curavit. Captación, uso y administración del agua en las ciudades de la Bética y el Occidente romano, Cádiz, 2010, pp. 37-39.

BELTRÁN LLORIS, FRANCISCO. "Irrigación y organización del territorio en la antigua Cascantum y el testimonio de la lex rivi Hiberiensis", en Navarra en la Antigüedad: propuesta de actualización. Pamplona: Institución Príncipe de Viana, ANDREU, J., (ed.), 2006, pp. 230 ss.

BIREBENT, JeAn. Aquae Romanae. Recherches d'bydraulique romaine dans l'Est algérien, Algérie, 1962, pp. 385-406.

BlanCH NOUguÉS, JosÉ MARÍA. "Acerca de las obligationes praediorum en la Tabula de Veleia". Hacia un Derecho Administrativo, Fiscal y Medioambiental Romano III, Madrid: 
Dykinson, A. Fernández de Buján (dir.), A. Trisciuglio y G. Gerez-Kraemer (coeds.), 2016.

BlanCH Nougués, José MaríA. "Observaciones acerca de la Tabula de Veleia", RGDR, 2014, disponible en: www.iustel.com

BlanCH Nougués, José MaríA. "Acerca de la organización administrativa de las fundaciones alimentarias públicas en Roma", en Hacia un derecho administrativo y fiscal romano, A. Fernández de BujÁn, G. Gerez Kraemer, B. Malavé Osuna (eds.), Madrid, Dykinson, 2011, pp. 209-226.

BlanCH NouguÉs, José María. Régimen jurídico de las fundaciones en derecho romano, Madrid, Dykinson, 2007.

Bueno Delgado, JuAn Antonio. "El bronce de Bonanza", AFDUA, 2004, pp. 154-165.

CAEs. Bellum Galli, 6,11, 2.

Capogrossi Colognesi, Luigi. "I sistemi delle servitù d'acqua in diritto romano", en Lex rivi biberiensis. Diritto e tecnica in una comunità di irrigazione della Spagna romana, Milán, Nápoles: Jovene editore, Università catolica del Sacro Cuore, L. MAGANZANI y CH. BuZZACHI (ed.), 2014, pp. 75-91.

Capogrossi Colognesi, Luigi. "Le forme gromatiche del territorio e vari regimi giuridici dell'ager Romanus e dell'ager colonicus. Il complesso mosaico della romanizzazione italica" en AA.VV., Gli statuti municipali, L. CAPOGROSSI COLOGNESI y E. GABBA (eds.), Pavía: IUSS Press, 2006, pp. 579-604.

Capogrossi Colognesi, Luigi. "Pagi sanniti e centuriatio romana", en Ager Campanus. Atti del Convegno internazionale, Real Sito di San Leucio, 8-9 de junio 2001, Nápoles: Jovene, G. FrANCIOSI (ed.), 2002, pp. 77-93.

Capogrossi Colognesi, LUIGI. Persistenza e innovazione nelle strutture territoriali dell'Italia romana, Nápoles, 2002.

Capogrossi Colognesi, Luigi. "Pagi, vici e civitates nell'Italia romana", en Iuris vincula. Studi in onore di Mario Talamanca I, Nápoles, 2001.

Castillo Pascual, María José. Espacio en orden: el modelo gromático de ordenación del territorio, Logroño: Universidad de La Rioja, 2011.

Castillo Pascual, María José. Opuscula Agrimensorum veterum, Logroño, Universidad de La Rioja, 2011.

ChOUQER, GÉRARD. "Arpentage, cadastre et fiscalité foncière, de l'Antiquité à l'époque moderne", Études rurales, vol. 181, n. ${ }^{\circ}$ 2008/1, 2008, pp. 203-236. 
Chouger, Gérard y Favory, FrançOIS. L'arpentage romain. Histoire des textes, Paris, 2001.

Christol, Michel. "Ressources des colonies, ressources de l'État", en Colons et colonies dans le monde romain, J. SCHEID y S. DEMOUGIN (eds.), Rome, 2013, pp. 65-86.

Cortijo Cerezo, María Luisa. "El pagus en la administración territorial romana. Los pagi de la Bética", Florentina Iliberritana, 2, 1991, pp. 105 ss.

Crintini, NiCOla. La tabula alimentaria de Veleia, Parma, 1991, disponible en: www.veleia.it

Curchin LeOnard A. "Vici and pagi in Roman Spain", Revue des Études Anciennes, 87, 1985 , pp. 340 ss.

D'Ors, Álvaro. Epigrafía jurídica de la España Romana, Madrid: Ministerio de Justicia y CSIC, 1953.

De Pachtère, FéliX-GeOrges. La table bypothécaire de Véléia, Paris, 1920.

De Pachtère, FéliX-Georges. "Le règlement d'irrigation de Lamasba", en Mel. d'Archéologie et d'Histoire, 28, 1908, pp. 373-405, disponible en : www.persee.fr/web/ revues/home/prescript/article/mefr_

De Tours, Gregorio, Historia francorum, 8, 18, disponible en: www.thelatinlibrary. com/gregorytours.html

Dictionnaire étymologique de la langue latine, Paris, A. ERnOUT y A. MEILLET (eds.), 1967.

Fernández de Buján, Antonio. Derecho Privado Romano, Madrid: Iustel, 8. a ed., 2015.

Fernández de Buján, Antonio. Derecho público romano, Cizur Menor (Navarra): Thomson Reuters Aranzadi, 18. ${ }^{a}$ ed., 2015.

FERnÁNDEZ DE BUJÁN, ANTONIO. "Testigos y documentos en la práctica negocial y judicial romana", RJUAM, n. ${ }^{\circ} 12,2005$, p. 125.

FESTO. "De verborum significatione", en BRUnS, Fontes Iuris Romani Antiqui, 6. a ed., Friburgo de Brigovia et Lipsiae, Th. Mommsen y O. Gradenwitz (ed.), 1893.

Giardina, Andrea y Grelle, Francesco. "La tavola di Trinitapoli", meFra, 95, 1983, pp. 249-303.

GÓmez PAnTOja, JOAQUín L. "No siempre la inscripción es lo más importante. Un bronce de Gallur (Zaragoza) y las tesserae pagi", en Hispania y la epigrafía romana. Cuatro perspectivas, RodríGUEZ-NeILA, J. F. (dir.), Faenza, 2009, pp. 105 ss.

GuILLÉN, José. Urbs Roma, II La vida pública, Salamanca: Sígueme, 1978, 60-63 y 186 ss. 
Hernández González, Fremiot. Un ensayo de clasificación del vocabulario técnico de los gromatici veteres del CAR, Madrid, Actas del X Congreso de la SEEC, 2001, pp. 121-128.

Hernández GonzÁlez, Fremiot. "Sobre el vocabulario técnico de la agrimensura" en Nova et vetera. Nuevos borizontes de la Filología latina, Madrid, 2002, 103-218.

HIGINO. De condicionibus agrorum.

HinRICHS, F. T., Die Geschichte der gromatischen Institutionem, Wiesbaden 1974, trad. fran., Histoire des Institutions gromatiques, Paris, 1989.

Le RouX, PATRICK. "Le pagus dans la péninsule Ibérique", Chiron, 39, 2009.

LeNEL, OTtO. Palingenesia iuris civilis, 2. . reimpr., Leipzig, 1889.

LO CASCIO, ELIO. "Il princeps e il suo impero. Studi di storia amministrativa e finanziaria romana", Documenti e studi, 26, Bari, 2000.

LuzZATTO, GiusepPe I. Tabularius, en NNDI, XVIII, Torino, 1971.

MAGANZANI, LAURETTA. Gli agrimensori nel processo privato romano, Roma, 1997.

MAGANZANI, LAURETTA. "Arpenter la terre pour le procès: la consultation technique en droit romain", RIDA, 53, 2006, pp. 284-298.

Martínez de Morentin, María Lourdes. "Aproximación al régimen jurídico de una comunidad de regantes: el Bronce de Agón", Hacia un derecho administrativo, fiscal y medioambiental romano III, Madrid: Dykinson A. FERnÁNDEZ DE Buján (dir.), A. Trisciuglio y G. GereZ-Kraemer (coeds.), 2016, pp. 323-349.

Martínez de Morentin, María Lourdes. "El decreto de L. Novius Rufus", RGDR, 26, 2016 (en prensa).

MarTinI, RemO. "Il pagus romano nella testimonianza di Siculo Flacco", en Rendiconti dell'Istituto Lombardo, Milano, vol. 107, n. ${ }^{\circ} 2$, 1973, pp. 1041-1056.

MAYer, MARC. "Antonio Agustín entre política y humanismo: reflexiones sobre su aportación a la Epigrafía", en Humanismo y pervivencia del mundo clásico. Homenaje al profesor Antonio Fontán, III.1, J. M. MAESTRE et al. (eds.), Alcañiz-Madrid: Instituto de Estudios Humanísticos-CSIC, 2002, pp. 359-364.

MENTXACA, ROSA. "Lex rivi Hiberiensis, derecho de asociación y gobernador provincial", RIDROM, 2009, pp. 1-46, disponible en: www.ridrom.com

MOATTI, Claude. Archives et partage de la terre dans le monde romain (II siècle avant - Ire siècle après J.C.), Rome, 1993. 
Papa, Giovanni. "Note sulla 'Tabula alimentaria di Veleia'", Labeo, vol. 40, n. ${ }^{\circ}$ 1, 1994, pp. 59-72.

PAVIS D'Escurac, Henriette. "Irrigation et la vie paysanne dans l'Afrique du Nord", en Ktéma 5, 1980, pp. 177-191.

PONS, JORDI. "Propiedad privada de la tierra y comunidades campesinas pirenaicas. Análisis de una sentencia judicial del año 193", Memorias de Historia Antigua, III, 1979, pp. 111-124.

RodríGuez NeIla, JuAn FranCisCO. "Ciudad y territorio en la provincia romana de la Bética", Florentia Iliberritana: Revista de Estudios de la Antigüedad clásica, 4-5, 1993 1994, pp. 445-484.

SANTANGElO, FeDERICO. "Confini di città e confini di pagi nell'Italia romana. Il problema del 'dualismo Limitaneo'", en Gli statuti municipali, CAPOGROSSI COLOGNESI, L. y GABBA, E. (dirs.), pp. 615-626.

Schulten, Adolf. "Die Landgemeinden im römischen Reich", en Pbilologus 53, 1894, pp. 629-634.

SHAW, BRENT. "Lamasba: An ancient irrigation community", en Antiquités Africaines 18, 1982, pp. 65-102.

SiCUlO FlaCCO, De condicionibus agrorum.

SISANI, SIMONE. In pagis forisque et conciliabulis. Le strutture amministrative dei distretti rurali in Italia tra la media repubblica e l'età municipale, Roma, Atti della Accademia Nazionale dei Lincei, serie IX, vol. XXVII, fasc. 2, 2011, pp. 551-780.

TARPIN, MICHEL. "A cosa serve un pagus? Bilancio e nuove questioni", en Tra l'Adriatico e le Alpi: forme e sviluppi dell'organizzazione territoriale e dei processi di integrazione nella X regio orientale e nelle regioni contermini, (Convegno, Udine, 3-5 ottobre 2012), S. MAGNANI (ed.), (en prensa).

TARPIN, MiCHEL. "La lex rivi Hiberiensis: une restitution graphique de l'incipit", en Zeitschrift für Papyrologie und Epigrapbik 192, 2014, pp. 265-272.

TARPIN, MICHEL. "Strutture territoriali romane: tra complessità ed efficienza", en 'Gallorum Insubrum fines': ricerche e progetti archeologici nel territorio di Varese, B. GRASSI e M. PIZZO (eds.), Roma, 2014, 199-207.

TARPIN, MICHEL. Vici et pagi dans l'occident romain, coll. EFR, Roma, 2002.

TORIBIO POlO, Gema. "Finalidad probatoria de la professsio censualis", RIDROM, 2012. 
Torrent, Armando. "Estructuras políticas menores en la Tarraconense de época adrianea: el pagus en la lex rivi Hiberiensis" RIDROM, 2014 (=IURA LXII, 2014).

TORRENT, ARMANDO. "Los magistri pagi de la Lex rivi Hiberiensis: naturaleza y funciones", RIDROM, 2013.

VARRÓN, De ling. Lat.

VinCi, Massimiliano. Fines regere. Il regolamento dei confini dall'età arcaica a Giustiniano, Milano, 2004. 